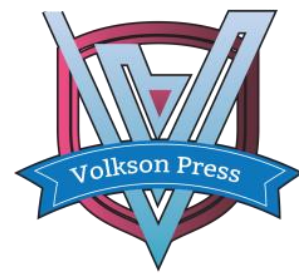

Contents List available at VOLKSON PRESS

Economics \& Management Innovations(EMI)

DOI : http://doi.org/10.26480/icemi.01.2017.119.120

\title{
Relationship between Urbanization and Environmental Pollution in China
}

\author{
Hedong Huang ${ }^{* 1,2}$, Dong $\mathrm{Li}^{\mathbf{1}}$ \\ 1.School of Management, Harbin Institute of Technology, Harbin , P.R. China ; \\ 2.Office of Party Committee , Hezhou University, Hezhou , P.R. China ) \\ *33128158@qq.com
}

This is an open access article distributed under the Creative Commons Attribution License, which permits unrestricted use, distribution, and reproduction in any medium, provided the original work is properly cited.

\section{ARTICLE DETAILS}

\section{Article History:}

Received 02 october 2017 Accepted 06 october 2017 Available online 11 october 2017

\section{Keywords:}

urbanization, environmental pollution, environmental Kuznets curve.

\section{ABSTRACT}

This paper aims to use the panel data of 31 provinces (autonomous regions and municipalities) in China from 2005 to 2014, to build a measurement model based on the environmental Kuznets curve hypothesis, and to make an empirical study on the relationship between urbanization and environmental pollution in China. The results show that therelationship between demographic urbanization and environmental pollution is anti-N-type curve, and the "double inflection point" is located at the demographic urbanization rate of $35.20 \%$ and $52.06 \%$. The spatial urbanization is positively correlated with environmental pollution. The economic urbanization is negatively correlated with environmental pollution. The life urbanization is weakly but positively correlated with environmental pollution.

\section{Introduction}

The relationship between urbanization and environmental pollution has become a crucial issue of urban sustainable development studies. The Environmental Kuznets Curve (EKC) hypothesis is used in the study of the relationship between urbanization and environmental pollution widely. Panayotou proposed the concept of EKC at the first time, that is, in the early stages of economic development, the environmental quality gradually deteriorated, until the economic development to a certain stage, the environmental quality gradually improved.So the relationship between economic development and environmental quality is an inverted U-shaped curve[1]. In recent years, some domestic scholars tried to confirm the relationship between urbanization and environmental pollution in different research area based on EKC hypothesis. The results showed that the curves were of various types such as an inverted U-shape, U-shape and anti-N-type etc[2-5].This paper aims to use the panel data of 31 provinces (autonomous regions and municipalities) in China from 2005 to 2014 , to take per capita soot emissions as dependent variable, demographic urbanization rate as the core explanatory variable, to take per capita built area, proportion of second \& third industry in GDP and per capita consumption expenditure of urban residents as control variables, to build a model based on the EKC hypothesis, to make an empirical study on the relationship between urbanization and environmental pollution in Chinese provinces.

\section{Establishment and analysis of measurement model}

\subsection{Establishment of measurement model}

The equations of EKC model are usually quadratic, cubic and logarithmic. This paper uses the cubic equation to set the measurement model of urbanization and environmental pollution as follows:

$e_{i t}=\alpha+\beta_{1} r_{i t}+\beta_{2} r_{i t}^{2}+\beta_{3} r_{i t}^{3}+\beta_{4} k_{i t}+\beta_{5} j_{i t}+\beta_{6} s_{i t}+\varepsilon_{i t}$

Where $e_{i t}$ is dependent variable, it indicates the per capita soot emissions of province i in the year of $\mathrm{t} . r_{i t}, r_{i t}^{2}$ and $r_{i t}^{3}$ are core explanatory variables, which indicate demographic urbanization rate, the square of demographic urbanization rate and the cube of demographic urbanization rate, respectively. $k_{i t}, j_{i t}$ and $S_{i t}$ are control variables, which indicate per capita built area space, proportion of second \& third industry in GDP, per capita consumption expenditure for urban residents, respectively. $\beta_{i}$ is the coefficient of each variable, $\alpha$ is the intercept items, $\varepsilon_{i t}$ is the disturbance items of dividual and time.

\subsection{Regression results of model}

The data of this paper are derived from China Statistical Yearbook and China Statistical Yearbook on Environment from 2006 to 2015.A few missing data are padded with interpolation. It should be used fixed effect model to estimate this short panel static model after the Hausman test[6]. The regression results show that the model is highly significant for the Pvalue of the whole model is 0.0001.In addition to the per capita consumption expenditure of urban residents, the coefficients of other variables were tested by $1 \%, 5 \%$, or $10 \%$, (as shown in table 1 ).

Table 1 Estimation results of model regression

\begin{tabular}{|l|l|l|l|l|}
\hline Variable & coef. & Std.Err & $\mathrm{t}$ & $\mathrm{P}>|\mathrm{t}|$ \\
\hline$r_{i t}$ & -.0523928 & 0251816 & -2.08 & 0.038 \\
\hline$r_{i t}^{2}$ & .0012474 & .0005006 & 2.49 & 0.013 \\
\hline$r_{i t}^{3}$ & -.0000095 & -.0000033 & -2.85 & 0.005 \\
\hline$k_{i t}$ & .3205718 & .1658266 & 1.93 & 0.054 \\
\hline$j_{i t}$ & -.0147401 & .0045665 & -3.23 & 0.001 \\
\hline$s_{i t}$ & .0000037 & .0000027 & 1.35 & 0.179 \\
\hline$\alpha$ & 2.211894 & .4918721 & 4.50 & 0.000 \\
\hline
\end{tabular}

\subsection{Analysis of regression result}

For the relationship between demographic urbanization and environmental pollution, as shown in table 1,the coefficients of $r_{i t}, r_{i t}^{2}$ and $r_{i t}^{3}$ is $-0.0523928,0.0012474,-0.0000095$, respectively, that is,$\beta_{1}<0$, $\beta_{2}>0, \beta_{3}<0$. It shows that the curve relationship between demographic urbanization and per capita soot emissions is anti-N-type, which has the characteristics of "double inflection point". The derivative of $r_{i t}$ on the equation (1) is $e_{i t}^{\prime}=\beta_{1}+2 \beta_{2} r_{i t}+3 \beta_{3} r_{i t}^{2}$, let $e_{i t}^{\prime}=0$, to calculate the two inflection points are: $r_{1}=35.20, r_{2}=52.06$. The regression results of the model show that when demographic urbanization 
rate is lower than $35.20 \%$, per capita soot emissions has improved with the increase of demographic urbanization rate. When demographic urbanization rate is between $35.20 \%$ and $52.06 \%$, per capita soot emissions has deteriorated with the increase of demographic urbanization rate. When the urbanization rate of demographic is higher than $52.06 \%$, per capita soot emissions has been improved with the increase of demographic urbanization rate.

For the demographic urbanization rate of Chinese provinces in 2014, the demographic urbanization rate in 18 provinces (autonomous regions and municipalities) including Shanghai, Beijing, and Tianjin is more than $52.06 \%$, but the demographic urbanization rate in Tibet is lower than $35.20 \%$, which is at the stage that per capita soot emissions has improved with the increase of demographic urbanization rate. The demographic urbanization rate in 12 provinces and autonomous regions including Jiangxi, Qinghai and Hebei is between $35.20 \%$ and $52.06 \%$, which shows that per capita soot emissions has deteriorated with the increase of demographic urbanization rate, (as shown in table 2 ).

Table 2 The demographic urbanization rate of Chinese provinces in 2014

\begin{tabular}{|c|l|l|l|}
\hline $\begin{array}{l}\text { Urbaniza } \\
\text { tion rate } \\
\text { interval }\end{array}$ & $\begin{array}{l}\text { Province \& demographic urbanization } \\
\text { rate(\%) }\end{array}$ & $\begin{array}{l}\text { Num } \\
\text { ber } \\
\text { of } \\
\text { provi } \\
\text { nces }\end{array}$ & $\begin{array}{l}\text { Propor } \\
\text { tion of } \\
\text { provin } \\
\text { ces(\%) }\end{array}$ \\
\hline $52.06 \%<$ & $\begin{array}{l}\text { Shanghai(89.6),Beijing(86.35),Tianjin( } \\
\text { 82.27),Guangdong(68), } \\
\text { Liaoning(67.05),Jiangsu(65.21),Zhejia } \\
\text { ng(64.87),Fujian(61.8), } \\
\text { Chongqing(59.6),Inner } \\
\text { Mongolia(59.5),Heilongjiang(58), }\end{array}$ & $\begin{array}{l}\text { Hubei(55.7),Shandong(55.01),Jilin(54. } \\
\text { 81),Hainan(53.8), } \\
\text { Shanxi(53.79),Ningxia(53.61),Shaanxi } \\
\text { (52.6) }\end{array}$ & 58.07 \\
\hline $35.20 \%<r$ & $\begin{array}{l}\text { Jiangxi(50.22),Qinghai(49.78),Hebei(4 } \\
\text { 9.33),Hunan(49.28), } \\
\text { Anhui(49.15),Sichuan(46.3),Xinjiang( } \\
\text { 46.07),Guangxi(46.01), } \\
\text { Henan(45.2),Yunnan(41.73),Gansu(41 } \\
\text { 68),Guizhou(40.01) }\end{array}$ & 12 & 38.71 \\
\hline $0<r \leq 35$ & Tibet(25.75) & 1 & 3.22 \\
\hline
\end{tabular}

For the relationship among spatial, economy, life urbanization and environmental pollution, as shown in table 1 , the coefficient of per capita built area space is more than zero, which indicates that the relationship between per capita built area space and per capita soot emissions is positive correlation, that is, with the increase of per capita area, a large number of agricultural land turn into industrial development and urban construction land, environmental pollution further deteriorated. The coefficient of proportion for second \& third industry in GDP is less than zero, which indicates that the relationship between second \& third industry in GDP and per capita soot emissions is negative correlation, that is, with the increase of proportion for non-agricultural industries, environmental pollution further improved. The coefficient of per capita consumption expenditure of urban residents is more than zero. Although the P-value is 0.179 , it also indicates that the relationship between per capita consumption expenditure of urban residents and per capita soot emissions is weakly but positive correlation, that is, with the increase for per capita consumption expenditure of urban residents, environmental pollution gradually deteriorated.

\section{Conclusion and Suggestions}

This paper study on the relationship between urbanization and environmental pollution in China. It can draw the following conclusions.First, the relationship between demographic urbanization and environmental pollution is anti-N-type in Chinese provinces. The "double inflection point" is located at the demographic urbanization rate of $35.20 \%$ and $52.06 \%$.Second, the relationship between spatial urbanization and environmental pollution is positively correlated,whereas the relationship between economic urbanization and environmental pollution is negatively correlated. The relationship between life urbanization and environmental pollution is weakly but positively correlated.

Methods of coordinated development between urbanization and ecology environment should be sought to realize healthy and sustainable development of urbanization. Some suggestions are as follows.First of all, it is necessary to define cities position clearly and to plan reasonable demographic layout so that some industries can be transferred to suburbs to achieve the demographic urbanization and the population pressure caused from the central area of the city can be relieved to realize the coordinated development of population, industry and environment.Second, it is necessary to use the land intensively and expand urban space moderately, make scientific and reasonable development plan of urbanization, define urban boundary clearly, utilize the development between urban and suburb area, revitalize the land stock, control the land increase, maintain a moderate scale of urban space, and improve the efficiency and quality of urbanization. Third, it must speed up the pace of adjusting industrial structure,develop High-tech industries and modern service industry actively.Modern industry system with lowemission, low consumption and high efficiency should be established to improve the quality of economic development.At last,education should be strengthened to lead and carry forward ecological civilization, and cultivate the culture of ecological environment in order to raise people's consciousness to form the consumption habits of low-carbon, environmental protection and recycling.

\section{References}

[1]Panayotou T. Empirical tests and policy analysis of environmental degradation at different stages of economic development. International Labour Organization,1993.

[2]Jiang Du,Yu Liu,Urbanization and environmental pollution: empirical study base on provincial panel data of China. Journal of resources and environment in the Yangtze river basin,2008 (11):825-830.

[3]Jiating Wang , Xuan Wang.The relationship between urbanization and environmental pollution in China-an empirical analysis based on 28 provinces panel data. Journal of urban problem,2010 (11) : 9-15.

[4]Shuiping Li,Dan Zhang.Kuznets curve of urbanization and environmental pollution in Hunan province.Journal of systems engineering,2014 (1) :152-158.

[5]Xiaolan Deng,Minghao Ju,Baodong Chen. Environmental pollution effects and influencing factors of urbanization in China.Exploring economic problem, 2017 (1):31-37.

[6]Qiang Chen.Advanced econometrics and Stata applications.Beijing: Higher education press,2014.

[7] Lei Hu,Junfeng Wang. Analysis of the long term impact of carbon dioxide emissions and short-term fluctuation effect of urbanization in Chian.Journal of arid land resources and environment, 2016 (8):94-100.

[8]Zhixiong Weng, Zhongyu Ma, Chazhong Ge, et al. Analysis on urban environmental effect driven by multi-factors of China.China population,resources and environment, 2017 (3): 63-73 